\title{
Quranic Language Politeness Education in the Era of the Industrial Revolution 4.0
}

\author{
T. Silvana Sinar ${ }^{1 *}$, Syahron Lubis ${ }^{1}$, Thyrhaya Zein ${ }^{1}$, Nurlela, Zulfan ${ }^{2}$ \\ ${ }^{1}$ Department of English Literature Faculty of Cultural Sciences Universitas Sumatra Utara \\ ${ }^{2}$ Department of Arabic Literature Faculty of Cultural Sciences Universitas Sumatra Utara
}

*Email: tengkusilvana@usu.ac.id

\begin{abstract}
This paper aims to introduce the modesty model of the qurani language as an alternative foundation of the politeness theories of language that have been taught so far. This model is important to be applied in the life of industrial revolution society 4.0. Fundamentally the industrial revolution 4.0 has caused changes in the way humans live, think, and interact in establishing relationships with one another. In turn this era has disrupted various human activities. These include language activities which are a form of social interaction. The phenomenon of impoliteness, harassment (bullying), and verbal violence is increasingly massive in the real world. Even the industrial revolution 4.0 which provides easy internet access and advances in information technology has also led to an increase in the phenomenon of hate speech, the dissemination of hoaxes and cyber bullying that can threaten social harmony and the unity of the multicultural Indonesian nation. Therefore it is necessary to develop a polite language education model based on religious teachings.
\end{abstract}

Keyword: Politeness, Qurani, Industrial Revolution, Disruption

\begin{abstract}
Abstrak
Tulisan ini bertujuan untuk memperkenalkan model kesantunan berbahasa qurani sebagai fondasi alternatif dari teori-teori kesantunan berbahasa yang telah diajarkan selama ini. Model ini penting untuk diaplikasikan di dalam kehidupan masyarakat revolusi industri 4.0. Secara fundamental revolusi industri 4.0 telah mengakibatkan berubahnya cara manusia hidup, berpikir, dan berinteraksi dalam menjalin hubungan satu dengan yang lain. Pada gilirannya era ini telah mendisrupsi berbagai aktivitas manusia. Termasuk di antaranya adalah aktifitas berbahasa yang merupakan wujud dari interaksi sosial. Fenomena ketidaksantunan, perundungan (bullying), dan kekerasan verbal kian masif terjadi di dunia nyata. Bahkan revolusi industri 4.0 yang menyediakan kemudahan akses internet dan kemajuan teknologi informasi juga telah menyebabkan peningkatan fenomena ujaran kebencian, penebaran berita bohong dan cyber bullying yang dapat mengancam harmoni sosial dan keutuhan persatuan bangsa Indoesia yang multikultural. Oleh sebab itu diperlukan pengembangan model pendidikan berbahasa santun yang berlandaskan kepada ajaran agama.
\end{abstract}

Kata Kunci: Kesantunan, Qurani, Revolusi Industri, Disrupsi

\section{PENDAHULUAN}

Undang-Undang Republik Indonesia nomor: 20 tahun 2003 tentang Sistem Pendidikan Nasional (UU Sisdiknas) merumuskan fungsi dan tujuan pendidikan nasional yang harus digunakan dalam mengembangkan upaya pendidikan di Indonesia. Pasal 3 UU Sisdiknas menyebutkan, "Pendidikan nasional berfungsi mengembangkan dan membentuk watak serta peradaban bangsa yang bermartabat dalam rangka mencerdaskan kehidupan bangsa, bertujuan untuk berkembangnya potensi peserta didik agar menjadi manusia yang beriman dan bertakwa kepada Tuhan Yang Maha Esa, berakhlak mulia, sehat, berilmu, cakap, kreatif, mandiri, dan menjadi warga negara yang demokratis serta bertanggungjawab".

Perumusan tujuan pendidikan nasional tersebut sangat tepat jika diaplikasikan pada era globalisasi seperti saat ini. Alasannya adalah bahwa arus globalisasi dan dinamika masyarakat industri 4.0 yang didominasi oleh ketersedian dan keterbukaan informasi serta kemajuan teknologi 
telah menciptakan tatanan masyarakat baru dan budaya global. Lebih-lebih narasi revolusi industri 4.0 telah mendisrupsi berbagai bentuk aktivitas manusia dalam berbagai dimensi kehidupan. Tidak hanya pada dimensi ekonomi, politik, hukum, dan pendidikan, tetapi juga pada dimensi sosiokultural bangsa Indonesia saat ini. Faktanya terlihat jelas bahwa pergeseran pola hidup masyarakat dewasa ini memiliki perubahan yang signifikan. Pada akhirnya dinamika tersebut, menciptakan efek dehumanisasi, demoralisasi, dekulturalisasi pada tatanan kehidupan bangsa Indoensia.

\section{Fenomena Kebahasaan Di Era Disrupsi}

Dalam praktiknya , bahasa memiliki beragam fungsi, diantaranya adalah fungsi transaksional dan interaksional. Fungsi transaksional terkait dengan penggunaan bahasa yang dimaksudkan untuk mengungkapkan amanat, yang mencakup pengungkapan gagasan, pikiran, perasaan, hasrat hati, dan sikap serta mencakup penmyampaian informasi-informaso faktual. Adapun fungsi interaksional adalah penggunaan bahasa untuk menciptakan dan mempertahankan hubungan sosial, baik dalam konteks intrakelompok maupun konteks antarkelompok. Fungsi interaksional inilah yang sangat penting dalam kehidupan manusia untuk menciptakan hubungan yang harmonis. Lebih-lebih dalam kehidupan masyarakat Indonesia yang multikultural.

Faktanya, praktik berbahasa dalam era disrupsi seperti saat ini telah mengalami pergeseran dan perubahan yang signifikan. Fungsi transaksional lebih menonjol ketimbang fungsi interaksional. Akibatnya, fenomena ketidaksantunan, perundungan (bullying), dan kekerasan verbal kian masif terjadi di dunia nyata. Bahkan revolusi industri 4.0 yang menyediakan kemudahan akses internet dan kemajuan teknologi informasi juga telah menyebabkan peningkatan fenomena ujaran kebencian, penebaran berita bohong dan cyber bullying yang dapat mengancam harmoni sosial dan keutuhan persatuan bangsa Indoesia yang multikultural.

Setidaknya, ada beberapa catatan kasus kebahasan yang perlu diantisipasi efeknya secara dini. Misalnya, Peningkatan jumlah kasus bullying yang dilaporkan ke Komisi Perlindungan Anak Indonesia sejak 2011 sampai 2017 mencapai 26.000 ribu kasus (http://www.kpai.go.id/berita/kpai-terima-aduan-26-ribu-kasus-bully-selama-2011-2017). Selain itu, dilaporkan pula bahwa $40 \%$ kasus bunuh diri anak Indonesia disebabkan perilaku bullying (Mensos RI, https://www.liputan6.com/news/read/2361551/mensos-bunuh-diri-anak-indonesia-40persen-karena-bullying). Sebagai tambahan, hasil penelitian dari beberapa peneliti, menyebutkan bahwa generasi muda dan anak-anak Indonesia telah mengalami degradasi kesantunan berbahasa (Kusno, 2014; Cahyaningrum, 2018).

\section{METODE PELAKSANAAN}

Berbahasa bukanlah kemampuan yang datang begitu saja atau dibawa sejak lahir, kemampuan berbahasa diperoleh melalui pendidikan. Semakin terdidik seseorang, semakin berkualitas pula kemampuan berkomunikasinya. Dalam kaitan berbahasa, maka out put pendidikan umum adalah manusia yang mampu mengadopsi nilai budaya masyarakat sekitarnya dalam hal berbahasa. Pendidikan bahasa pada dasarnya adalah pendidikan bahasa dan penggunaan bahasa. Dalam kalimat lain, pendidikan bahasa dilakukan untuk mengajarkan peserta didik tentang bahasa yang baik dan benar secara gramatikal, dan mengajarkan kepada mereka penggunaan bahasa yang sopan dan santun demi terwujudnya hubungan yang harmonis antarpartisipan.

Selaras dengan amanah sistem pendidikan nasional di atas, yang bertujuan untuk berkembangnya potensi peserta didik agar menjadi manusia yang beriman dan bertakwa kepada Tuhan Yang Maha Esa, berakhlak mulia, dan berilmu, maka dalam perspektif Islam, pendidikan dan pendidikan bahasa juga bertujuan untuk mewujudkan manusia yang bertaqwa, beriman, berakhlak mulia, sopan dan santun serta mampu menyerukan kebaikan dan mencegah kemungkaran. Dari kesamaan tujuan sistem pendidikan nasional dan pendidikan Islam itu, diusulkan sebuah model pendidikan kesantunan bahasa Qurani. Yaitu pendidikan kesantunan berbahasa yang sarat dengan nilai-nilai transendental-ilahiah dan ihsaniah sehingga membentuk ideologi kebahasaan humanismeteosentris. 
Humanisme dalam hal ini adalah humanisme Islam yang menjunjung tinggi nilai-nilai kemanusiaan karena hakikatnya ajaran Islam merupakan ajaran fitrah yang memang untuk memenuhi kebutuhan manusia. Adapun teosentrisme mencakup seluruh aspek kehidupan yang terpusat kepada Tuhan. Dalam pandangan Islam humanisme tidak dapat dipisahkan dari prinsip teosentrisme. Di satu sisi keimanan "tauhid" sebagai inti ajaran Islam, menjadi pusat seluruh orientasi nilai. Di sisi lain aktualisasi keimanan itu mesti terpancar dalam berbagai aktifitas seorang muslim, termasuk di dalamnya adalah aktifitas berbahasa sehingga tujuan risalah Islam itu benarbenar tercapai yaitu Islam yang rahmatan lil alamin.

Model kesantunan bahasa qurani ini digali dari prinsip-prinsip kesantunan berbahasa yang terkandung di dalam Alquran. Konsep dan model kesantunan bahasa qurani ini diusulkan untuk melengkapi fondasi pemikiran para linguis yang menyatakan bahwa kesantunan berbahasa dipengaruhi oleh faktor sosial dan budaya (Cutting, 2002; Eelen, 2006; Leech, 2014). Padahal, lebih dari itu, kesantunan berbahasa dapat diajarkan berdasarkan faktor Dīnun atau agama.

\section{HASIL DAN PEMBAHASAN}

Secara ringkas disampaikan enam prinsip berbahasa secara santun di dalam Alquran . Enam prinsip itu adalah pertama, qaulan sadidan (Q.S An-Nisa: 9; Al-Ahzab: 70) yaitu berbicara secara benar dan jujur; kedua, qaulan balighan (Q.S An-Nisa: 63), yaitu berbicara efektif; ketiga, qaulan ma'rufan (Q.S An-Nisa: 5, 8; Al-Baqarah: 235; Al-Ahzab: 32) yaitu berbicara menggunakan kata-kata yang baik, yang enak dirasa oleh jiwa, yang menimbulkan rasa tentram di dalam hati; keempat, qaulan kariman (Q.S Al-Isra': 23) yaitu berbicara dengan kata-kata mulia yang membesarkan hati dan menimbulkan kegembiraan; kelima, qaulan layyinan (Q.S Thaha: 44) yaitu berbicara dengan menggunakan kata-kata yang lemah lembut; keenam, qaulan maysuran (Q.S Al-Isra': 28) yaitu berbicara menggunakan kata-kata yang baik, pantas dan mudah dimengerti.

Aplikasi Model Kesantunan Bahasa Qurani (dikembangkan dari model kesantunan Leech, 2014)

Kesantunan qaulan sadida (perkataan yang jelas) dapat dilakukan dengan strategi menambahi nilai opini untuk lain. Kesantunan qaulan ma'rufa (perkataan baik, santun, dan menyenangkan) dapat dilakukan dengan strategi menambahi nilai keinginan untuk lain, mengurangi nilai keinginan untuk lain, mengurangi nilai kualitas untuk diri, menambahi nilai kewajiban dari diri untuk lain, mengurangi nilai opini untuk diri. Kesantunan qaulan baligha (perkatan benar dan efektif) dapat dilakukan dengan strategi menambahi nilai opini untuk lain. Kesantunan qaulan maysura (perkataan yang mudah) dapat dilakukan dengan strategi mengurangi nilai keinginan untuk diri, dan strategi menambahi nilai opini untuk lain. Kesantunan qaulan layyina (perkataan yang menyentuh hati) dapat dilakukan dengan mengaplikasikan strategi mengurangi nilai opini untuk diri. Kesantunan qaulan karima (perkataan yang mulia) dapat dilakukan dengan mengaplikasikan strategi kesantunan mengurangi nilai keinginan untuk diri, dan strategi menambahi nilai kualitas untuk lain.

Berikut ini adalah beberapa contoh dari pengaplikasian model kesantunan berbahasa qurani.

- Mengucapkan salam.

"Selamat pagi".

"Assalamualaikum Warahamatullahi Wabarakatuhu, selamat pagi”.

- Mengucapkan terima kasih.

"Terima kasih ya".

"Terima kasih atas bantuannya".

"Alhamdulillah, terima kasih atas bantuannya".

- Berjanji.

"Ia, nanti malam saya datang".

"Insya Allah, nanti malam saya datang".

- Menjelaskan

"Wallahu a'lamu, semoga yang saya sampaikan benar".

- Mengucapkan selamat ulang tahun. 
"Selamat ulang tahun ya".

"Barakallah, selamat ulang tahun ya.

- Memohon.

"Bantulah".

"Tolong dibantu ya"

Kesantunan Bahasa Qurani Sebagai Border Line Untuk Fenomena Bahasa Di Era Disrupsi

Telah disebutkan di atas, bahwa terdapat berbagai bentuk praktik kebahasaan di era disrupsi yang sedang menjangkiti masyarakat Indonesia saat ini. Sebagai masyarakat mayoritas, umat Islam di Indonesia mesti memberikan tindakan atau aksi yang solutif untuk menghadapi fenomenafenomena kebahasaan tersebut. Hal ini perlu agar tidak menjadi paradoks bahwa jumlah umat muslim yang besar belum mampu menghadirkan dan menciptakan pendidikan bahasa yang lebih Islami di lembaga-lembaga pendidikan Islam. Oleh sebab itu pendidikan berbahasa (secara santun) mesti berlandaskan kepada ajaran agama yang fitrah. Ajaran yang menjunjung tinggi nilai-nilai kemanusian (humanis-hablum minannasi-horizontal) dan didasari oleh nilai-nilai ketuhanan (teosentris-hablum minallahi-vertikal).

Beranjak dari pemikiran tersebut, setiap tuturan seorang muslim mesti berlandaskan keihsanan. Keihsanan adalah kata yang berasal dari bahasa Arab yaitu Ihsān yang memiliki arti kebaikan. Terkait dengan praktik berbahasa, seorang, muslim bukan hanya mesti menampilkan kesantunan berbahasa, tetapi juga mesti mesti menampilkan keihsanan berbahasa. Jika kesantunan berbahasa selalu terkait dengan faktor konteks sosial dan kultural, maka keihsanan berbahasa terkait dengan faktor ketiga yaitu faktor Dīnun atau faktor agama. Jadi keihsanan berbahasa lebih kompleks karena menyertakan faktor agama dalam praktik berbahasa.

Dalam ajaran Islam Ihsān merupakan bagian atau cakupan dari Dīnun (baca An-Nawawi, 2000, 118; Matondang, 2017: 159). Penjelasan itu dapat dilihat dari hadis nabi Muhammad s.a.w yang diriwayatkan oleh Imam Muslim tentang Dīnun yang terbagai atas tiga bagian yaitu İmān, Islām dan Ihsān. Dīnun secara komprehensif dapat dipahami sebagai pengakuan bahwa hanya Allah s.w.t Tuhan Yang Maha Kuasa, dan seluruh aktifitas hambanya merupakan bentuk pengabdian kepadaNya, yang dilakukan semata-mata untuk mengharapkan keridaan-Nya (periksa Maududi, 2003: 160; 1983: 92).

Adapun ihsān menurut Imam al-'Izz Ibn Abdu as-Salam (2003: 122) adalah setiap apapun dari ajaran Islam baik lahir maupun batin yang mendatangkan maslahah (kebaikan) dan menolak mafsadah (keburukan dan kerusakan), baik di dunia maupun di akhirat (lihat juga Matondang, 2017: 160). Selain dari pada itu, Ihsān, juga direpsentasikan sebagai ajaran tentang akhlak, baik itu akhlak kepada Allah sebagai khaliq maupun kepada manusia dan hewan sebagai makhluk-Nya. Menurut Kuntowijoyo (1997: 84) agama (Dīnun) berbeda dengan ideologi. Dalam agama (Dīnun) ada sistem dosa-pahala, surga-neraka, dan halal-haram, serta benar-salah. Ditambahnya, bahwa dalam agama (Dīnun) segala perbuatan tergantung dari iman seseorang. Sedangkan ideologi tidak mengenal halhal itu.

Berdasarkan uraian di atas tentang keterkaitan Dīnun dan Ihsān dan secara langsung berkorelasi dengan penggunaan bahasa, dan jika merujuk kepada multistrata pengunaan bahasa dalam konteksnya (konteks linguistik dan konteks sosial) seperti yang digagas oleh para pakar Linguistik Fungsional Sistemik, maka konsep ihsān ini terletak setingkat di atas ideologi. Untuk jelasnya perhatikanlah gambar di bawah ini.

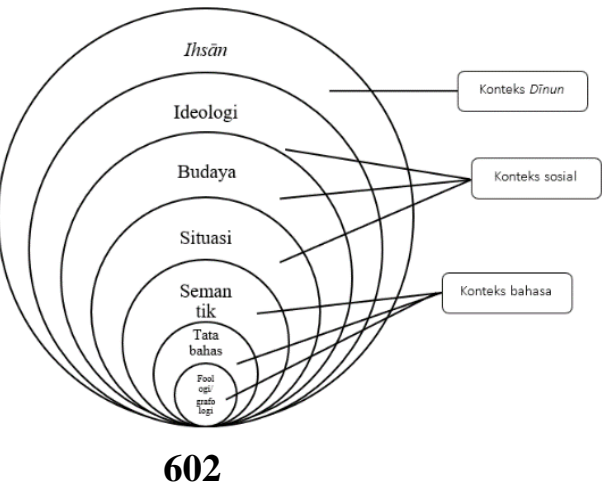


Gambar 3.1. Keterkaitan konteks bahasa, konteks sosial dan konteks agama.

Terkait dengan multisrata penggunaan bahasa yang diusulkan oleh pakar Linguistik Fungsional Sistemik, bagi Norman Fairclough tokoh analisis wacana kritis dan linguistik kritis lain yang terpengaruh oleh pemikiran M.A.K Halliday, meneybutkan bahwa berbahasa dipandang sebagai bentuk praktik sosial. Bagi mereka tidak ada teks yang netral. Semuanya memiliki nilai-nilai ideologi, kekuasaan, dan dominasi. Hal itu, berbeda dengan perspekstif Islam bahwa berbahasa mesti berpahala. Berbahasa bukan hanya sekadar praktik sosial. Jika ia praktik sosial maka tak mengapa jika seorang penutur dapat berbohong dan menebarkan kebencian. Sebaliknya, dalam perspektif Islam hal itu tidak dibenarkan. Ada begitu banyak ayat Alquran dan hadis Nabi Muhammad s.a.w yang menyerukan agar manusia berbahasa secara santun dan baik. Dari situ lahirlah istilah keihsanan berbahasa. Sebagai border line untuk tindakan berbohong, bullying verbal, penebaran berita bohong, dan penebaran ujaran kebencian. Kesantunan berbahasa saja tidak cukup karena tak jarang seorang penutur berbohong untuk menyenangkan mitra tuturnya. Lebih-lebih untuk menyembunyikan maksud-maksud tertentu. Bertopang dari fakta itu, dibutuhkan keihsanan berbahasa sehingga bahasa tidak saja sebagai praktik sosial, tetapi lebih dari itu berbahasa sebagai praktik Ibadah.

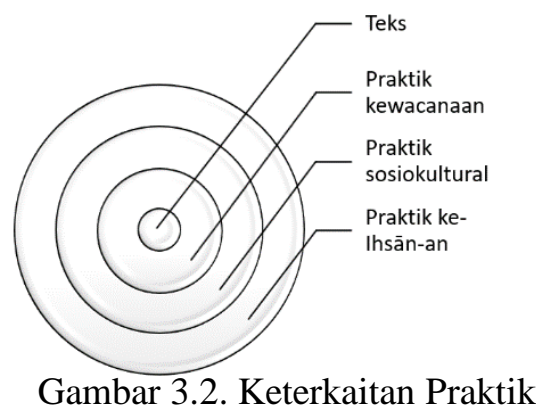

\section{KESIMPULAN}

Undang-Undang Republik Indonesia nomor: 20 tahun 2003 tentang Sistem Pendidikan Nasional (UU Sisdiknas) merumuskan fungsi dan tujuan pendidikan nasional yang harus digunakan dalam mengembangkan upaya pendidikan di Indonesia. Pasal 3 UU Sisdiknas menyebutkan, "Pendidikan nasional berfungsi mengembangkan dan membentuk watak serta peradaban bangsa yang bermartabat dalam rangka mencerdaskan kehidupan bangsa, bertujuan untuk berkembangnya potensi peserta didik agar menjadi manusia yang beriman dan bertakwa kepada Tuhan Yang Maha Esa, berakhlak mulia,

sehat, berilmu, cakap, kreatif, mandiri, dan menjadi warga negara yang demokratis serta bertanggungjawab".

Perumusan tujuan pendidikan nasional tersebut sangat tepat jika diaplikasikan pada era globalisasi seperti saat ini. Alasannya adalah bahwa arus globalisasi dan dinamika masyarakat industri 4.0 yang didominasi oleh ketersedian dan keterbukaan informasi serta kemajuan teknologi telah menciptakan tatanan masyarakat baru dan budaya global. Lebih-lebih narasi revolusi industri 4.0 telah mendisrupsi berbagai bentuk aktivitas manusia dalam berbagai dimensi kehidupan. Tidak hanya pada dimensi ekonomi, politik, hukum, dan pendidikan, tetapi juga pada dimensi sosiokultural bangsa Indonesia saat ini. Faktanya terlihat jelas bahwa pergeseran pola hidup masyarakat dewasa ini memiliki perubahan yang signifikan. Pada akhirnya dinamika tersebut, menciptakan efek dehumanisasi, demoralisasi, dekulturalisasi pada tatanan kehidupan bangsa Indonesia.

Praktik berbahasa dalam era disrupsi seperti saat ini juga telah mengalami pergeseran dan perubahan yang signifikan. Fungsi transaksional lebih menonjol ketimbang fungsi interaksional. Akibatnya, fenomena ketidaksantunan, perundungan (bullying), dan kekerasan verbal kian masif terjadi di dunia nyata. Bahkan revolusi industri 4.0 yang menyediakan kemudahan akses internet dan kemajuan 
teknologi informasi juga telah menyebabkan peningkatan fenomena ujaran kebencian, penebaran berita bohong dan cyber bullying yang dapat mengancam harmoni sosial dan keutuhan persatuan bangsa Indoesia yang multikultural.

Selaras dengan amanah sistem pendidikan nasional di atas, yang bertujuan untuk berkembangnya potensi peserta didik agar menjadi manusia yang beriman dan bertakwa kepada Tuhan Yang Maha Esa, berakhlak mulia, dan berilmu, maka dalam perspektif Islam, pendidikan dan pendidikan bahasa juga bertujuan untuk mewujudkan manusia yang bertaqwa, beriman, berakhlak mulia, sopan dan santun serta mampu menyerukan kebaikan dan mencegah kemungkaran. Dari kesamaan tujuan sistem pendidikan nasional dan pendidikan Islam itu, diusulkan diterapkannya pendidikan etika kesantunan bahasa Qurani khususnya untuk mencegah terjadinya perilaku bullying di lingkungan lembaga pendidikan.

Hal ini perlu agar tidak menjadi paradoks bahwa jumlah umat muslim yang besar belum mampu menghadirkan dan menciptakan pendidikan bahasa yang lebih Islami di lembaga-lembaga pendidikan Islam. Oleh sebab itu pendidikan berbahasa (secara santun) mesti berlandaskan kepada ajaran agama yang fitrah. Berlandaskan kepada kandungan Alquran. Ajaran yang menjunjung tinggi nilai-nilai kemanusian (humanis-hablum minannasi-horizontal) dan didasari oleh nilai-nilai ketuhanan (teosentris-hablum minallahi-vertikal).

\section{UCAPAN TERIMAKASIH}

Tim pelaksana kegiatan pengabdian kepada masyarakat mengucapkan terima kasih kepada Lembaga Pengabdian Kepada Masyarakat USU yang telah mendanai kegiatan ini.

\section{DAFTAR PUSTAKA}

Astuti, P. R. (2008). Meredam bullying. 3 cara efektif mengatasi kekerasan pada anak. Jakarta: Gramedia Widiaswara Indonesia.

Chaer, Abdul. 2010. Kesantunan Berbahasa. Jakarta: Rineka Cipta.

Sauri Sofyan. 2006. Pendidikan Berbahasa Santun. Bandung PT Genesindo.

Al-Buruswi, Ismail H. 1996. Terjemahan Tafsir Ruhul Bayan Juz. 5. Bandung: CV. Diponegoro.

Al-Maraghi. 1943. Tafsir Al-Maraghi. Beirut: Dar El Fikr.

Amir. M. 1987. Etika Komunikasi Masa Dalam Pandangan Islam. Jakarta. Logos.

Ashddiqi, H. 1977. Tafsir Al-Bayan Jilid 1 dan 2. Bandung: Al-Maarif.

Al-Thabari, J. 1988. Jamiu al-bayan an ta'wili al-qur'an Juz 4,5, 15, 16, 22. Beirut: Dar El Fikr.

Hamka. 1987. Tafsir Al-Azhar. Jakarta: Bulan Bintang.

Katsir, Ibnu. t.t. Tafsir Ibn Katsir. Riyadh. Maktabah Ma'arif.

Pranowo.(2009). Berbahasa Secara Santun. Yogyakarta: PustakaPelajar.

Prasetyo, A. B. K. (2011). Bullying di sekolah dan dampaknya bagi masa depan anak. El-Tarbawi Jurnal Pendidikan Islam, Vol IV, No 1 .

Qarni, Waizul. 2014. "Pendekatan Persuasif untuk Efektivitas Dakwah" dalam Siregar, Muhammad Habibi dan Joko Susanto,Dakwah Humanis. Medan: Citapustaka Media. 
Rakhmat. J. 1985. Psikologi Komunikasi. Bandung: Remaja Rosdakarya.

Salmadanis. 2014. "Aplikasi Dakwah Lisan dan Uswah Al-Hasanah" dalam Siregar, Muhammad Habibi dan Joko Susanto, Dakwah Humanis. Medan: Citapustaka Media.

Saefullah, Ujang. 2007. Kapita Selekta Komunikasi: Pendekatan Agama dan Budaya. Bandung: Simbiosa Rekatama Media.

Sari, Eva Purnama dan Sufriani. 2017. Faktor Yang Mempengaruhi Bullying Pada Anak Usia Sekolah Di Sekolah Dasar Kecamatan Syiah Kuala Banda Aceh. Idea Nursing Journal, Vol. 8 (3).

Sauri, Sofyan. 2006. Pendidikan Berbahasa Santun. Bandung: PT Genesindo.

Sejiwa. 2008. Bullying: Mengatasi Kekerasan di Sekolah dan Lingkungan Sekitar Anak. Jakarta: Grasindo.

Shihab. Q. 1985. Membumikan Al-Quran. Bandung Mizan.

Sholikhin, Muhammad. 2013. Islam Rahmatan Lil 'Alamin: Panduan Dakwah Umat Islam Indonesia dalam Konteks Kekinian, Mewujudkan Amar Makruf Nahi Mungkar, Menepis Terorisme. Jakarta: Elex Media Komputindo.

Siregar, Muhammad Habibi dan Joko Susanto. 2014. Dakwah Humanis. Medan: Citapustaka Media. 